\title{
Does attitude similarity serve as a heuristic cue for kinship? Evidence of an implicit cognitive association
}

\author{
Justin H. Park*, Mark Schaller \\ Department of Psychology,University of British Columbia, 2136 West Mall, Vancouver, BC, Canada V6T 1Z4 \\ Initial receipt 30 June 2004; final revision received 26 August 2004
}

\begin{abstract}
Using methods of experimental cognitive psychology, we tested the hypothesis that attitude similarity serves as a heuristic cue signaling kinship, which may motivate kin-recognition responses (e.g., prosocial behavior) even to unrelated individuals. The experiment employed a reaction-time methodology to assess cognitive associations between specific target individuals and kinship cognitions. Results revealed that, relative to targets with dissimilar attitudes, attitudinally similar targets were automatically linked to kinship cognitions. This effect was especially strong among perceivers who more strongly trusted their intuitions, indicating that the similarity-kinship connection is based on heuristic impressions, not rational decision making. Additional results showed that the activation of kinship cognitions was correlated with perceivers' willingness to help similar others. These findings add to our understanding of proximate mechanisms linked to kin selection processes and implicate the role of kinship processes in prosocial behavior toward unrelated strangers as well. (C) 2005 Elsevier Inc. All rights reserved.
\end{abstract}

Keywords: Attitude similarity; Kin recognition; Kin selection; Kinship; Prosocial behavior

\section{Introduction}

Evolved social cognitive mechanisms have well-defined design features that yield specific hypotheses about their operation in contemporary contexts (Barkow, Cosmides, \&

* Corresponding author. Tel.: +1 604734 2910; fax: +1 6048226923.

E-mail address: jpark@psych.ubc.ca (J.H. Park). 
Tooby, 1992; Buss, 1994; Kurzban \& Leary, 2001; Schaller, Park, \& Faulkner, 2003). Among these cognitive mechanisms are those pertaining to kinship. Given that interactions with kin have been central to individual survival and reproduction throughout evolutionary history, humans surely evolved psychological mechanisms designed to facilitate the recognition of kin and to behaviorally discriminate kin and nonkin (Daly, Salmon, \& Wilson, 1997). The present investigation focused on the psychology of kin recognition. We tested the hypothesis that attitude similarity serves as a perceptual cue that signals kinship. Consequently, even when we encounter a total stranger, if that stranger shares our attitudes, we may automatically think of that person in ways that suggest kinship. The activation of these kinship cognitions may, in turn, facilitate more prosocial responses toward that person.

\subsection{Proximate mechanisms of nepotistic discrimination}

Kin selection theory (Hamilton, 1964) has provided a useful overarching framework guiding much of the research on kin relations and prosocial behavior. Studies of prosocial behavior confirm the basic tenets of kin selection theory: Animals tend to assist those that are more closely related to them (e.g., Sherman, 1977). Of course, to treat kin preferentially, individual organisms must have some means of distinguishing kin from nonkin. A wide variety of proximate mechanisms facilitate kin recognition (Porter, 1987; Waldman, 1987). In general, kin recognition depends on the perception of specific cues, such as spatial location, familiarity, and similarity, that, while correlated with actual kinship during evolutionary history, may not be perfectly reliable. Under most natural circumstances, these cue-based mechanisms produce behaviors that generally conform to the normative rules implied by kin selection theory (Hamilton, 1964); but they may also lead to predictable errors. Because kin recognition is cue dependent, and because many cues are less than perfectly reliable, the operation of kin-recognition mechanisms inevitably tricks organisms sometimes into responding toward kin as nonkin and (perhaps even more often) toward nonkin as kin.

Humans are no exception to this general set of principles. People provide more assistance to kin than to nonkin and are more inclined to help closer kin than more distant kin (Burnstein, Crandall, \& Kitayama, 1994; Essock-Vitale \& McGuire, 1985; Kruger, 2003). Several basic psychological mechanisms facilitate these nepotistic tendencies. Even young children grasp notions of kinship and its implications (Springer, 1992), and researchers have identified universals underlying the psychology of kinship (Daly et al., 1997; Jones, 2003). One thing is clear: Psychological representations of kin and nonkin are not simply a product of rational assessments of genetic relatedness. Like other animals, people use a set of signals as indicators of kinship. Some of these signals exist in individuals' emotional states. For instance, the subjective and emotion-laden feeling of closeness appears to serve as a kinship cue. More genetically similar individuals arouse stronger subjective feelings of closeness, and people's willingness to help kin seems to be mediated, in part, by this subjective experience (Korchmaros \& Kenny, 2001; Neyer \& Lang, 2003). Furthermore, it has been argued that empathy is an emotional kinship cue that motivates prosocial action (Hoffman, 1981; Krebs, 1987; Preston \& de Waal, 2002). 
These sorts of affective experiences may provide the impetus for functional action. But the arousal of emotions must depend on the detection of other, more primary perceptual and cognitive cues. Just what are these cues? Some are rooted in basic sensory systems. Children can identify their siblings by smell, for instance, and mothers can use olfactory cues to identify and discriminate their children (Porter \& Moore, 1981). Other cues involve somewhat higher order cognitive processes. These cues tend to fall into two broad classes: those that connote familiarity and those that connote similarity.

The clearest instance of familiarity is early coresidence. The simple rule "if we grew up together, then you are kin" is ubiquitous across species (Porter, 1987; Wilson, 1987). Unrelated people who grow up together seem to view one another as kin despite knowledge to the contrary, and as a result, find each other unattractive as sexual partners (Lieberman, Tooby, \& Cosmides, 2003; Shepher, 1971; Wolf, 1970). People also report higher perceived kinship for genetically unrelated step-kin than for acquaintances (Burnstein et al., 1994). At a more heuristic level, terms such as "fraternity," "brotherhood," and "soul sisters" are often used to arouse emotions normally reserved for kin. For instance, political speech is especially evocative when it employs these sorts of kin terms (Johnson, Ratwik, \& Sawyer, 1987; Salmon, 1998).

Similarity also serves as a kinship cue. Among many species, kinship is diagnosed through phenotype matching - a process in which target individuals are compared against a "kin prototype" (Porter, 1987). A kin prototype encompasses many traits, such as facial appearance, that serve as cues to phenotypic similarity. Among humans, there is evidence that fathers favor children that look most like them (Burch \& Gallup, 2000). This phenomenon generalizes to nonkin as well: Adults report greater willingness to assist unrelated children who happen to have facial features in common with their own (DeBruine, 2004; Platek, Burch, Panyavin, Wasserman, \& Gallup, 2002; Platek et al., 2003). Facial similarity also enhances interpersonal trust (DeBruine, 2002). People may be attentive to additional superficial similarities as kinship cues. For instance, people are more likely to assist someone who shares their name or has similar fingerprints, especially if the shared feature is perceived as uncommon (Burger, Messian, Patel, del Prado, \& Anderson, 2004; Oates \& Wilson, 2002).

Other kinds of similarities might also signal kinship, but there is little research that directly addresses this issue. Indeed, most of the relevant research on human kin recognition uses methods (e.g., the assessment of prosocial behavior) that only indirectly tap into the underlying cognitive psychology of kinship. The experiment reported below addressed these lacunae by investigating whether attitude similarity can serve as a kinship cue, using methods that more directly assessed kinship-relevant cognitions.

\subsection{Attitude similarity as a kinship cue}

If apparent phenotypic similarities serve as kinship cues, then kinship might be heuristically signaled by similarity in attitudes. Several lines of evidence suggest that this hypothesis is plausible.

First, many attitudes are, to some extent, phenotypic manifestations of underlying genetic substrates. Although there is considerable variability in the extent to which attitudes are 
heritable, behavior genetics research reveals that dozens of common attitudes reflect the influence of genes (Eaves, Eysenck, \& Martin, 1989; Olson, Vernon, Harris, \& Jang, 2001). That is, closely related individuals generally do have more highly similar attitudes. The relationship between genetic similarity and attitude similarity is imperfect, of course, but it is positive. Just as shared physiognomy can be helpful (if not perfectly reliable) in distinguishing kin from nonkin, so too can shared attitudes. Consistent with this notion, the similarity-attraction link is stronger for attitudes higher in heritability (Tesser, 1993).

Second, people often respond to attitudinally similar others in a manner that parallels responses to actual kin. Perceived attitude similarity is associated with greater levels of liking and positive affect (Byrne et al., 1971; Chen \& Kenrick, 2002; Rosenbaum, 1986). Perceived similarity in attitudes and other traits is also associated with higher levels of empathy and prosocial behavior (e.g., Batson, Duncan, Ackerman, Buckley, \& Birch, 1981; Krebs, 1975; Suedfeld, Bochner, \& Matas, 1971). Given the link between attitude similarity and prosocial behavior, evidence documenting a link between attitude similarity and kinship cognitions (and between kinship cognitions and prosocial tendencies) may contribute to conceptual frameworks that link evolutionary processes to the psychological bases of contemporary prosocial behavior (e.g., Krebs, 1987; Van Vugt \& Van Lange, in press).

\subsection{Overview of the present study}

Many investigations of kinship processes focus on perceptions of and reactions to actual kin. This makes a lot of sense. But to rigorously test the hypothesis that attitude similarity serves as a heuristic kinship cue, it is necessary to experimentally separate attitude similarity from other cues that may also be associated with genetic relatedness. Doing so requires using a methodology in which perceivers are presented with previously unknown nonkin targets. Evidence supporting the hypothesized cue-based kin-recognition process can be obtained if perceivers respond more positively to targets displaying the hypothesized cue than to targets not displaying the cue (e.g., DeBruine, 2002; Oates \& Wilson, 2002). However, evidence of a more affectively positive response by itself cannot unequivocally support the activation of psychological mechanisms pertaining to kinship. More direct evidence supporting the hypothesis requires the measurement of responses that are not merely positive, but more specific to the concept of kinship.

With these considerations in mind, we designed a study in which we introduced participants to two unknown target individuals. One target individual was depicted as attitudinally similar to the participants; the other was depicted as dissimilar. We then assessed the extent to which, in the perceivers' minds, these two target individuals were differentially associated with cognitions specific to kinship, and with positive cognitions more broadly.

To do so, we employed a reaction-time method called the Implicit Association Test (IAT; Greenwald, McGhee, \& Schwartz, 1998; Greenwald, Nosek, \& Banaji, 2003). The IAT has been used in previous research to assess implicit cognitive associations between social categories (e.g., Black) and semantic concepts (e.g., unpleasant). In the present investigation, the IAT was used to assess associations between specific target individuals and semantic concepts. Participants performed two different IAT tasks. One IAT task assessed the extent to 
which the attitudinally similar target person (relative to the dissimilar target person) was implicitly linked to the semantic concept "family." If, indeed, attitude similarity serves as a kinship cue, then there should be evidence of this cognitive linkage.

It is possible, however, for this implicit cognitive linkage to emerge spuriously as the result of psychological responses that are conceptually irrelevant to kinship. The semantic concept "family" surely has a positive connotation, and similar others may arouse positive cognitions for a variety of reasons. Consequently, a tendency to link the family concept to the similar target person could result indirectly as a byproduct of a more immediate tendency to associate the similar target person with pleasant thoughts of a nonspecific nature. To test this alternative explanation, participants also completed a second IAT task that assessed the extent to which the similar target person (relative to the dissimilar target person) was implicitly linked to a broader class of pleasant concepts. Obtaining these two indices allowed us to assess whether the similar other is associated merely with pleasantness or, more specifically, with family.

In addition to these methods, we also assessed individual differences in the tendency to make reflexive, intuitive judgments. If human kin recognition is - like many other evolved processes - rooted in psychological mechanisms that respond automatically to heuristic cues, then the automatic activation of kinship cognitions may be especially strong among individuals who, in general, allow themselves to trust their intuitions.

We also asked participants to provide self-report reactions to the target individuals to assess the relationships between implicit cognitions and explicit judgments and responsessuch as willingness to help the similar and dissimilar target persons.

\section{Method}

\subsection{Participants}

Forty-five students (29 women and 16 men) from the University of British Columbia participated in exchange for extra credit in undergraduate psychology courses. (Data from 2 additional students were excluded because they did not complete the computer tasks correctly.)

\subsection{Procedure}

Participants first completed a practice IAT task to become familiar with the computerbased procedures to be used later in the experimental session. They then completed several questionnaires assessing selected demographic variables and individual differences. One of these questionnaires assessed individual differences in Faith in Intuition (Epstein, Pacini, Denes-Raj, \& Heier, 1996). This questionnaire asks participants to indicate their level of agreement with 12 statements that assess the extent to which they trust their hunches, intuitive feelings, and first impressions (e.g., "When it comes to trusting people, I can usually rely on my 'gut feelings"').

Participants also completed a brief attitudes questionnaire. This questionnaire presented them with five statements relevant to particular issues or activities (e.g., death penalty for 
murder). Participants were asked to indicate their own attitudes by rating (on 6-point rating scales) their level of agreement with each statement. Approximately half the participants were presented with high-heritability attitude items, the rest with low-heritability items (taken from Olson et al., 2001.) Previous research reveals that people express greater liking for others who are similar on more highly heritable attitudes (Tesser, 1993), suggesting the hypothesis that participants in the high-heritability condition might display especially strong implicit associations linking the similar other to kinship and to positive cognitions in general. However, no support was found for this hypothesis: Statistical analyses revealed no effect of heritability on implicit associations.

Upon completion of these questionnaires, participants were introduced to two fictional female individuals, Elaine and Carol. They were shown three photos of Elaine and three photos of Carol; these photos were subsequently used as stimuli in the IAT tasks. (All photos were headshots obtained from the Internet. The two women were similar in age and attractiveness, and the pairing between the photos and the names was counterbalanced across participants to eliminate any systematic tendency to perceive either of the women in a more positive manner.) Participants were asked to recall their own responses on the attitudes questionnaire and were asked to "imagine that Elaine gave the same responses as you, and imagine that Carol responded very differently." To further stimulate participants' imagination, they were asked to guess how Elaine might have responded on three additional attitude items. As a result of these procedures, participants acquired visual representations of two individuals - one individual imagined to be attitudinally similar (Elaine), the other individual attitudinally dissimilar (Carol).

Participants then completed two IAT tasks. The IAT is a computer-based reaction-time task in which, over the course of many trials, participants are presented with a specific stimulus (either a word or a photo) and are asked to categorize each stimulus item into one of two categories by pressing specified keys, with either the left or right index finger, on the computer keyboard. The computer records the elapsed time from stimulus onset to key-press, and these reactions times can be used to draw inferences about implicit cognitive associations between different kinds of stimulus items. (For more extensive descriptions of this methodology and its applications, see Greenwald et al., 1998, 2003.)

For one task (family IAT), participants judged whether the stimulus photos depicted Elaine or Carol and also categorized words (brother, family, kin, kinship, mother, sister; distant, outcast, outsider, stranger, unfamiliar, and unknown) as connoting either family or stranger. (In pretesting, 20 additional participants rated the pleasantness of these stimulus words on a 10-point scale with endpoints labeled very unpleasant and very pleasant. The mean pleasantness rating was 8.30 for the six family words and 3.96 for the six stranger words.) There were two critical blocks, consisting of 40 trials each. In one block, the response categories Elaine and family shared one response key on the keyboard, whereas Carol and stranger shared another response key. If the attitudinally similar other (Elaine) is cognitively associated with kinship cognitions, then this particular response-key arrangement is psychologically consistent, resulting in shorter reaction times. In the other critical block of trials, Elaine and stranger shared one response key, whereas Carol and family shared another response key. If the attitudinally similar other (Elaine) is 
cognitively associated with kinship cognitions, then this particular response-key arrangement is psychologically conflicting, which is manifest in relatively longer reaction times. The greater the cognitive association between Elaine and family, the greater the divergence in average reaction times across the two critical blocks. Therefore, the difference in average reaction times across the two blocks of trials serves as an indicator of implicit cognitive association (we refer to this here as the IAT effect). Larger IAT effects in this task indicate stronger cognitive activation of kinship cognitions in response to an attitudinally similar other.

Participants also completed another IAT task (pleasant IAT) that assessed implicit associations between Elaine and pleasant. The procedure for the pleasant IAT task was identical to that of the family IAT task, except that participants judged a different set of stimulus words: friend, joy, kind, laughter, peace, trust; dirty, failure, hate, hostile, stupid, and terrible. These words are irrelevant to kinship relations, but they are all evaluatively positive or negative in a broader sense. (In pretesting, the mean pleasantness rating was 9.20 for the six pleasant words and 2.42 for the six unpleasant words. Thus, these words were more extreme in positive-negative valence than the stimulus words used in the family IAT, described above.) Participants categorized these words as either pleasant or unpleasant. Larger IAT effects on this task indicate stronger cognitive activation of positive cognitions in response to an attitudinally similar other.

Participants completed both IAT tasks; the order was counterbalanced. After the IAT tasks, the participants completed additional questionnaires. One questionnaire reintroduced the attitude items and asked participants to indicate how important each attitude was to them and how strongly they held each attitude. (Consistent with previous research, Tesser, 1993, high-heritability attitude items were considered more important and were held more strongly; these results are not germane to the present article.) Another questionnaire asked three questions about Elaine and Carol: (1) to what extent participants could see things from Elaine's and Carol's perspective; (2) to what extent participants would be willing to assist Elaine and Carol should they require help; and (3) to what extent they thought they shared genes with Elaine and Carol. Participants indicated their responses on six-point rating scales.

\section{Results}

To calculate implicit associations linking the target individuals to semantic concepts, we used a scoring algorithm that minimizes the biasing effects of extremely short or long reaction times, and of individual differences in response speed (Greenwald et al., 2003). The resulting values are akin to standardized effect sizes. More positive values on the two IAT indices indicate stronger implicit cognitive associations linking the attitudinally similar other (Elaine) to family and to pleasant concepts.

Results revealed that both IAT effects were positive. The attitudinally similar target person was, relative to the dissimilar other, implicitly associated with family $(M=.24, p<.001)$. In addition, the attitudinally similar target person was implicitly associated with pleasant 
$(M=.23, p<.001)$. The strength of these two IAT indices did not differ $(p>.50)$, nor were these two indices substantially correlated $(r=.23, p=.13)$. Two aspects of these results are noteworthy. First, there was a clear tendency to implicitly associate an attitudinally similar target person with kinship concepts. Second, this implicit association was no less strong than the association linking the attitudinally similar other to positive thoughts in general. This is especially notable, given that the stimulus words in the pleasant IAT task were more affectively extreme than those in the family IAT task - and hence, the pleasant IAT effect is the better indicator of any tendency to associate similarity with positivity. Thus, the family IAT effect cannot be explained simply as a byproduct of the similarity-pleasant association. Indeed, the weak correlation between the two IAT indices suggests that the tendency for similarity to trigger kinship cognitions is largely independent of its tendency to trigger positive cognitions in general.

The unique relation between attitude similarity and kinship cognitions is further clarified by additional analyses examining the moderating effects of a conceptually relevant individual-difference variable. Faith in Intuition was positively correlated with the family IAT index $(r=.33, p=.03)$ but not with the pleasant IAT index $(r=.05, p=.72)$. Regression lines associated with these two relations are presented in Fig. 1. Participants who reported that they tend to rely on first impressions and gut feelings to navigate their social world showed an especially strong tendency to associate the attitudinally similar target person with kinship cognitions. Those who placed little trust in intuitions (and, hence, are more likely to use rational thought to overrule automatically activated gut feelings) did not show this tendency. No such moderating effect occurred on the pleasant IAT effects; that is, the tendency to respond intuitively was not related to the tendency to automatically link the similar stranger to pleasantness in general. These results not only provide further evidence against the possibility that the activation of kinship cognitions is merely a byproduct of more general positive thoughts, but also indicate that the activation of kinship cognitions - in response to an attitudinally similar target person-results from a reflexive, nonrational cognitive mechanism.

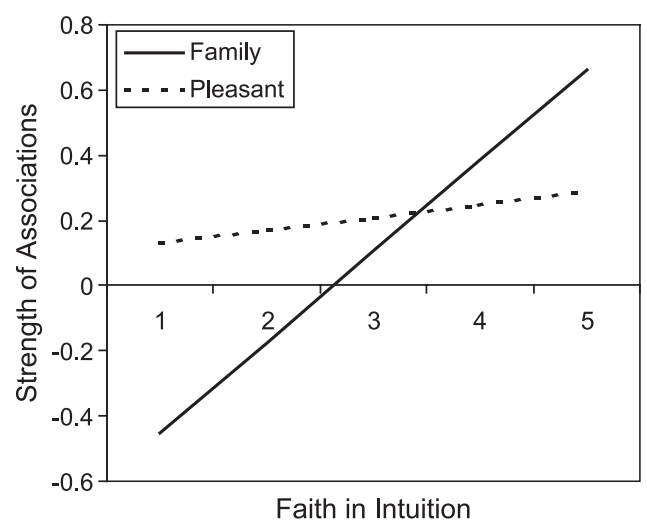

Fig. 1. Regression lines indicating predictive effects of Faith in Intuition on implicit associations linking similar other to family and to pleasant. 
Participants answered three additional questions about Elaine and Carol concerning the ease of perspective taking, willingness to help, and estimation of shared genes. Not surprisingly, Elaine was given higher ratings than Carol for all three questions (all $p \mathrm{~s}<.001$ ). Further analyses examined whether these judgmental discriminations between the similar (Elaine) and dissimilar (Carol) target persons were correlated with implicit associations. To do so, we calculated a difference score for each question by subtracting the rating of Carol from the rating of Elaine so that higher values indicate judgmental discrimination in favor of the attitudinally similar target person. Discrimination on the perspective-taking judgment was positively predicted by the family IAT index $(r=.32, p=.03)$ but not by the pleasant IAT index $(r=-.16, p=.29)$. A regression analysis in which the two IAT indices were entered as predictors revealed that the impact of the family IAT index remained strong $(\beta=.38, p=.01)$. Similarly, discrimination in willingness to help was more strongly predicted by the family IAT index $(r=.33, p=.03)$ than by the pleasant IAT index $(r=.22, p=.15)$. An analogous regression analysis indicated that the impact of the family IAT index remained strong $(\beta=.30$, $p=.05)$. These results suggest that the automatic activation of kinship cognitions is associated with empathic and prosocial responses to attitudinally similar others. In contrast, discrimination in estimates of shared genes was more strongly correlated with the pleasant IAT index $(r=.25, p=.09)$ than the family IAT index $(r=.12, p=.42)$. This result suggests that the activation of kinship cognitions is entirely separate from any rational assessment of genetic relatedness. Given the crudeness of these three questions, we would be wise to draw only tentative conclusions from these simple correlations. But the tentative conclusions are provocative: Kinship cognitions (activated by the perception of attitudinal similarity) may promote prosocial responses to total strangers.

\section{Discussion}

The perception of attitudinally similar people activates kinship cognitions, and this effect is found primarily among individuals who respond reflexively with intuition-based judgments. These results are consistent with the hypothesis that attitude similarity serves as a heuristic (and therefore fallible) kinship cue. Additional results indicate that the effects on kinship cognitions are unlikely to be a mere byproduct of the general tendency to view similar people positively. Results revealed that the implicit similarity-kin association predicted the ease of taking the similar person's perspective and willingness to help the similar person. Interestingly, the tendency to implicitly associate the similar other with pleasant concepts had no relation to either ease of perspective taking or willingness to help. These results implicate a link between automatically activated kinship cognitions and prosocial responses - a link that, because of its heuristic nature, may operate even in interactions between total strangers.

These findings are preliminary, but they add a deeper conceptual texture to the social psychological literature documenting positive consequences of attitude similarity-including effects on liking, perspective taking, empathy, and helping behavior (e.g., Batson et al., 1981; Byrne et al., 1971; Krebs, 1975). There are surely multiple psychological processes that 
account for these effects. It seems likely that one of these processes is rooted in the psychology of kin recognition. More than commonly recognized, the psychology of kinship may subtly influence behavior in a wide variety of social settings that, from a rational perspective, have nothing to do with kinship.

These findings complement other research on kin-recognition mechanisms (e.g., DeBruine, 2002; Lieberman et al., 2003; Oates \& Wilson, 2002; Platek et al., 2002, 2003). It is increasingly clear that kin recognition depends on heuristic cue-based processes that often operate outside the realm of conscious awareness or rational thought. As the list of documented kinrecognition cues lengthens, it will become important to more fully explore the nature of the specific cue-based responses. Some cues may operate at a more rational level of analysis than others, for instance. Also, cues that were more highly correlated with actual kinship during evolutionary history are likely to be more psychologically powerful. For instance, attitude similarity was likely a much less reliable kinship cue than coresidence is; consequently, the impact of attitude similarity on kinship cognitions may be weaker and more contextually variable. It is less clear how attitude similarity compares with other kinds of similarity cues, such as those based on shared names or shared facial physiognomy. These are questions for future research to resolve.

The methods employed in our study offer a useful means of addressing these and other questions pertaining to kin-recognition cues. Compared with behavioral measures (e.g., decisions about help giving), the assessment of implicit cognitive associations offers a more direct means of assessing the extent to which perceptual information signals kinship. This is not to suggest that this cognitive methodology should replace behavioral methods. Behavioral data are necessary to forge conceptual connections between the evolutionary process and the psychology of kin recognition. But additional measures are also needed to dig more deeply into the cognitive processes that compel behavior. Consider, for instance, the speculation that the capacity for empathy evolved in response to kin selection pressures (Hoffman, 1981; Krebs, 1987; Preston \& de Waal, 2002; Schaller, 2003). This speculation is consistent with a large psychological literature documenting both the antecedents of empathy and its consequences on helping behavior, including helping outside of actual kin relations (e.g., Batson et al., 1981; Krebs, 1975; Krebs \& Miller, 1985). But to date, there has been no research that directly addresses a more specific question that lies at the center of the theoretical speculation: Does the experience of empathy serve as an emotional kinship cue? The methods we used to study the kin-signaling implications of attitude similarity might profitably be deployed to address this important question about empathy as well.

More generally, investigations of the psychology of kin recognition represent an important part of inquiry into the evolutionary process of kin selection and its consequences. It is one thing to know that a capacity for helping behavior can evolve as a consequence of the probabilistic logic of inclusive fitness (Hamilton, 1964); it is quite a different thing to know how that capacity actually functions. Proximate mechanisms that facilitate discrimination between kin and nonkin are essential because there is no ordinary means of directly "reading" the genes of others (Daly et al., 1997; Dawkins, 1976, 1979; Krebs, 1987). Kin recognition depends on inferences from necessarily imperfect perceptual cues and is therefore fallibleoften, it seems, in an overinclusive manner. Consider reed warblers: The heuristic equation 
between "chicks in my nest" and "my own genetic offspring" is highly reliable but not always perfect. Consequently, warblers that employ this heuristic rule may not only contribute to the welfare of their own offspring, but also of parasitic cuckoos that exploit the rule. The evolved psychology of human beings is likewise prone to the use (and overuse) of similar heuristics.

\section{Acknowledgments}

This research was supported by a research grant from the Social Sciences and Humanities Research Council of Canada and a graduate fellowship from the University of British Columbia. We are grateful for the support. We thank Dennis Krebs, Susan Huang, and Mark Van Vugt for their assistance and/or helpful advice.

\section{References}

Barkow, J., Cosmides, L., \& Tooby, J. (1992). The adapted mind: evolutionary psychology and the generation of culture. New York: Oxford University Press.

Batson, C. D., Duncan, B. D., Ackerman, P., Buckley, T., \& Birch, K. (1981). Is empathic emotion a source of altruistic motivation? Journal of Personality and Social Psychology, 40, 290-302.

Burch, R. L., \& Gallup, G. G., Jr. (2000). Perceptions of paternal resemblance predict family violence. Evolution and Human Behavior, 21, 429-435.

Burger, J. M., Messian, N., Patel, S., del Prado, A., \& Anderson, C. (2004). What a coincidence! The effects of incidental similarity on compliance. Personality and Social Psychology Bulletin, 30, 35-43.

Burnstein, E., Crandall, C., \& Kitayama, S. (1994). Some neo-Darwinian decision rules for altruism: weighing cues for inclusive fitness as a function of the biological importance of the decision. Journal of Personality and Social Psychology, 67, 773-789.

Buss, D. M. (1994). The evolution of desire: strategies of human mating. New York: Basic Books.

Byrne, D., Gouaux, C., Griffitt, W., Lamberth, J., Murakawa, N., Prasad, M. B., et al. (1971). The ubiquitous relationship: attitude similarity and attraction: a cross-cultural study. Human Relations, 24, 201-207.

Chen, F., \& Kenrick, D. T. (2002). Repulsion or attraction? Group membership and assumed attitude similarity. Journal of Personality and Social Psychology, 83, 111-125.

Daly, M., Salmon, C., \& Wilson, M. (1997). Kinship: the conceptual hole in psychological studies of social cognition and close relationships. In J. A. Simpson, \& D. T. Kenrick (Eds.), Evolutionary social psychology (pp. 265-296). Mahwah, NJ: Erlbaum.

Dawkins, R. (1976). The selfish gene. New York: Oxford University Press (New ed., 1989).

Dawkins, R. (1979). Twelve misunderstandings of kin selection. Zeitschrift für Tierpsychologie, 51, 184-200.

DeBruine, L. M. (2002). Facial resemblance enhances trust. Proceedings of the Royal Society of London. Series B, 269, 1307-1312.

DeBruine, L. M. (2004). Resemblance to self increases the appeal of child faces to both men and women. Evolution and Human Behavior, 25, 142-154.

Eaves, L. J., Eysenck, H. J., \& Martin, N. G. (1989). Genes, culture and personality: an empirical approach. San Diego, CA: Academic Press.

Epstein, S., Pacini, R., Denes-Raj, V., \& Heier, H. (1996). Individual differences in intuitive-experiential and analytical-rational thinking styles. Journal of Personality and Social Psychology, 71, 390-405.

Essock-Vitale, S. M., \& McGuire, M. T. (1985). Women's lives viewed from an evolutionary perspective: II. Patterns of helping. Ethology and Sociobiology, 6, 155-173. 
Greenwald, A. G., McGhee, D. E., \& Schwartz, J. L. K. (1998). Measuring individual differences in implicit cognition: the Implicit Association Test. Journal of Personality and Social Psychology, 74, 1464-1480.

Greenwald, A. G., Nosek, B. A., \& Banaji, M. (2003). Understanding and using the Implicit Association Test: I. An improved scoring algorithm. Journal of Personality and Social Psychology, 85, 197-216.

Hamilton, W. D. (1964). The genetical evolution of social behaviour. Journal of Theoretical Biology, 7, 1-52.

Hoffman, M. L. (1981). Is altruism a part of human nature? Journal of Personality and Social Psychology, 40, $121-137$.

Johnson, G. R., Ratwik, S. H., \& Sawyer, T. J. (1987). The evocative significance of kin terms in patriotic speech. In V. Reynolds, V. Falger, \& I. Vine (Eds.), The sociobiology of ethnocentrism (pp. 157-174). London: Croom Helm.

Jones, D. (2003). The generative psychology of kinship: Part I. Cognitive universals and evolutionary psychology. Evolution and Human Behavior, 24, 303-319.

Korchmaros, J. D., \& Kenny, D. A. (2001). Emotional closeness as a mediator of the effect of genetic relatedness on altruism. Psychological Science, 12, 262-265.

Krebs, D. (1975). Empathy and altruism. Journal of Personality and Social Psychology, 32, 1134-1146.

Krebs, D. (1987). The challenge of altruism in biology and psychology. In C. Crawford, M. Smith, \& D. Krebs (Eds.), Sociobiology and psychology: ideas, issues, and applications (pp. 81-118). Hillsdale, NJ: Erlbaum.

Krebs, D. L., \& Miller, D. T. (1985). Altruism and aggression. In G. Lindzey, \& E. Aronson (Eds.), Special fields and applications (3rd ed.). Handbook of Social Psychology, vol. 2. (pp. 1-71). New York: Random House.

Kruger, D. J. (2003). Evolution and altruism: combining psychological mediators with naturally selected tendencies. Evolution and Human Behavior, 24, 118-125.

Kurzban, R., \& Leary, M. R. (2001). Evolutionary origins of stigmatization: the functions of social exclusion. Psychological Bulletin, 127, 187-208.

Lieberman, D., Tooby, J., \& Cosmides, L. (2003). Does morality have a biological basis? An empirical test of the factors governing moral sentiments regarding incest. Proceedings of the Royal Society of London. Series B, $270,819-826$.

Neyer, F. J., \& Lang, F. R. (2003). Blood is thicker than water: kinship orientation across adulthood. Journal of Personality and Social Psychology, 84, 310-321.

Oates, K., \& Wilson, M. (2002). Nominal kinship cues facilitate altruism. Proceedings of the Royal Society of London. Series B, 269, 105-109.

Olson, J. M., Vernon, P. A., Harris, J. A., \& Jang, K. L. (2001). The heritability of attitudes: a study of twins. Journal of Personality and Social Psychology, 80, 845-860.

Platek, S. M., Burch, R. L., Panyavin, I. S., Wasserman, B. H., \& Gallup, G. G., Jr. (2002). Reactions to children's faces resemblance affects males more than females. Evolution and Human Behavior, 23, 159-166.

Platek, S. M., Critton, S. R., Burch, R. L., Frederick, D. A., Myers, T. E., \& Gallup, G. G., Jr. (2003). How much paternal resemblance is enough? Sex differences in hypothetical investment decisions but not in the detection of resemblance. Evolution and Human Behavior, 24, 81-87.

Porter, R. H. (1987). Kin recognition: functions and mediating mechanisms. In C. Crawford, M. Smith, \& D. Krebs (Eds.), Sociobiology and psychology: ideas, issues, and applications (pp. 175-203). Hillsdale, NJ: Erlbaum.

Porter, R. H., \& Moore, J. D. (1981). Human kin recognition by olfactory cues. Physiology \& Behavior, 27, 493-495.

Preston, S. D., \& de Waal, F. B. M. (2002). Empathy: its ultimate and proximate bases. Behavioral and Brain Sciences, 25, 1-72.

Rosenbaum, M. E. (1986). The repulsion hypothesis: on the nondevelopment of relationships. Journal of Personality and Social Psychology, 51, 1156-1166.

Salmon, C. A. (1998). The evocative nature of kin terminology in political rhetoric. Politics and the Life Sciences, $17,51-57$.

Schaller, M. (2003). Ancestral environments and motivated social perception: goal-like blasts from the evolutionary past. In S. J. Spencer, S. Fein, M. P. Zanna, \& J. M. Olson (Eds.), Motivated social perception: the Ontario Symposium (pp. 215-231). Mahwah, NJ: Erlbaum. 
Schaller, M., Park, J. H., \& Faulkner, J. (2003). Prehistoric dangers and contemporary prejudices. European Review of Social Psychology, 14, 105-137.

Shepher, J. (1971). Mate selection among second generation kibbutz adolescents and adults: incest avoidance and negative imprinting. Archives of Sexual Behavior, 1, 293-307.

Sherman, P. W. (1977). Nepotism and the evolution of alarm calls. Science, 197, 1246-1253.

Springer, K. (1992). Children's awareness of the biological implications of kinship. Child Development, 63, 950-959.

Suedfeld, P., Bochner, S., \& Matas, C. (1971). Petitioner's attire and petition signing by peace demonstrators: a field experiment. Journal of Applied Social Psychology, 1, 278-283.

Tesser, A. (1993). The importance of heritability in psychological research: the case of attitudes. Psychological Review, 100, 129-142.

Van Vugt, M., \& Van Lange, P. A. M. (in press). Social psychological adaptations for social dilemmas: the evolution of human altruism and cooperation. In: M. Schaller, J. A. Simpson, \& D. T. Kenrick (Eds.), Evolution and social psychology. Philadelphia: Psychology Press.

Waldman, B. (1987). Mechanisms of kin recognition. Journal of Theoretical Biology, 128, 159-185.

Wilson, E. O. (1987). Kin recognition: an introductory synopsis. In D. J. C. Fletcher, \& C. D. Michener (Eds.), Kin recognition in animals (pp. 7-18). New York: Wiley.

Wolf, A. P. (1970). Childhood association and sexual attraction: a further test of the Westermarck hypothesis. American Anthropologist, 72, 503-515. 